\title{
Enabling Participation Income for an Eco-Social State
}

\author{
Francesco Laruffa* (D), Michael McGann** (D) and Mary P. Murphy*** \\ *University of Geneva, School of Social Sciences, Geneva, Switzerland. \\ E-mail: francesco.laruffa@unige.ch
}

**Maynooth University Social Sciences Institute, National University of Ireland, Maynooth, Ireland. E-mail: michael.mcgann@mu.ie

${ }^{* * *}$ Department of Sociology, National University of Ireland, Maynooth, Ireland.

E-mail: mary.p.murphy@mu.ie

We revise Atkinson's concept of a 'participation income' (PI), repositioning it as a form of green conditional basic income that is anchored in a capabilities-oriented eco-social policy framework. This framework combines the capability approach with an 'ethics of care' to re-shape the focus of social policy on individuals' capability to 'take care of the world', thus shifting the emphasis from economic production to social reproduction and environmental reparation. In developing this proposal, we seek to address key questions about the feasibility of implementing PI schemes: including their administrative complexity and the criticism that a PI constitutes either an arbitrary and confusing, or invasive and stigmatising, form of basic income. To address these concerns, we argue for an enabling approach to incentivising participation whereby participation pathways are co-created with citizens on the basis of opportunities they recognise as meaningful rather than enforced through strict monitoring and sanctions.

Keywords: Capabilities, eco-social policy, participation income, post-productivism, coproduction.

\section{Introduction}

The necessity of transitioning towards an 'eco-social' (Koch, 2018) welfare model is increasingly acknowledged. As argued in several contributions to this themed section (Gough, 2021; Koch, 2021), this will require re-anchoring welfare institutions in a 'postproductivist' architecture wherein income supports and public services are targeted at meeting essential needs rather than catalysing labour productivity and economic growth. While there is now a growing consensus about the need for such an eco-social policy agenda, there is far less agreement about what specific social policies might contribute to this reorientation. The role of social policy in enabling sustainable transitions remains marginal within the literature on decarbonisation (Bohnenberger, 2020) while the ecological impacts of social policies remain 'largely ignored' (Koch, 2018: 42) within mainstream social policy debates (Stamm et al., 2020). To rectify this double neglect, we revise the concept of a 'participation income' (PI) (Atkinson, 1996), positioning it as a form of 'green conditional basic income' (Bohnenberger, 2020: 596) that retains a commitment to the principle of reciprocity but affirms forms of reproductive and ecological labour (care 
for people, the environment and social-democratic institutions), and not just paid employment, as fulfilling participation requirements.

While early proposals positioned PI as a political compromise between the selectivism of workfarist social assistance and the unconditionality of universal basic income $(\mathrm{UBI})$ - a tactical accommodation that could clear the path towards unconditional welfare (Atkinson, 1996) - we advocate for PI as an important reform in its own right that aligns with a capabilities-oriented eco-social policy framework (McGann and Murphy, 2021). Building on these arguments, we advance a tactical proposal for an eco-social Pl, working on two dimensions. First, we reinforce the normative framework that underlines this proposal combining the capability approach (CA) with the 'ethics of care'. In this context, we argue that an eco-social PI should re-shape the focus of social policy on individuals' capability to 'take care of the world', thereby shifting the emphasis from production and employment to social reproduction and environmental reparation (Laruffa, 2021). Second, we strengthen the proposal of an eco-social PI demonstrating how it might be implemented from an administrative and political perspective. In so doing, we respond to two critiques of PI: those relating to the difficulty of implementing it administratively (because of its complexity and costs) and those pointing to the risk that a PI constitutes either an arbitrary and confusing or invasive and stigmatising policy (e.g., De Wispelaere and Stirton, 2007). To address these concerns, we argue that it is essential that citizens are involved in processes of co-production, whereby they actively participate in co-creating the participation requirements entailed in PI.

Clearly, a PI is not a panacea for resolving all challenges linked to the establishment of an eco-social welfare model but should be considered as one element of a broader set of policies, including, for example, an efficacious taxation policy on highly polluting luxury goods and on extreme wealth; an adequate industrial policy for moving employment from 'brown' to 'green' economic sectors; and sufficient investments in public infrastructures and services. Nonetheless, a PI may provide an important policy instrument in the promotion of such an eco-social welfare model.

We proceed by presenting the normative framework for an eco-social PI based on the capability approach (CA) and the ethics of care. We then review the key objections to PI on grounds of administrative feasibility before introducing the concepts of 'co-creation' and 'co-production', which we see as promising solutions to these challenges. To emphasise the administrative and political feasibility of this proposal, we draw on recent experiments in co-creating participation options with social assistance recipients in the Netherlands, Scotland, and Denmark, highlighting how these initiatives illustrate the potential for implementing the principle of reciprocity in a demand-oriented rather than compliancedriven way. We conclude by reflecting on the institutional contexts in which this proposal for a co-productive model of implementation may be most feasible, recognising the embeddedness of existing co-production initiatives in social-democratic structures and devolved administrative contexts with strong collaborative governance arrangements.

\section{Towards an eco-social PI centred on the 'capability to take care of the world'}

To normatively ground our proposal, we build on the CA and the feminist literature on the 'ethics of care'. The CA implies focusing public action on the expansion of people's capabilities, i.e. their real freedom to lead the kind of life they 'have reason to value' (Sen, 
1999: 18; Nussbaum, 2011) ${ }^{1}$. There are two main reasons for choosing the CA as a normative framework of reference for our proposal.

First, the CA has the potential to re-orient welfare reform beyond narrow concerns of employment-promotion, on the basis of two arguments (Laruffa, 2020). On the one hand, from a capability perspective, not only employment but also other activities, such as care work and civic engagement, are considered valuable forms of participation that social policy should support. On the other hand, employment is valuable only if it positively contributes to human flourishing. Thus, the link between labour market inclusion and capability-expansion is not automatic and cannot be simply assumed. Combining these two arguments, we contend that work should be reconceptualised in a broad way to include other activities beyond employment and that social policy should be concerned with promoting meaningful work that sustains people's lives and the environmental and social conditions upon which they depend (cf. Deranty, 2021) rather than any type of work.

At this point, the CA can be usefully combined with the 'ethics of care', as developed by feminist theorists (e.g. Gilligan, 1993; Tronto, 2013). An ethics of care emphasises the social and political value of caring as a human activity and highlights the importance of human connections, interdependence, reciprocity, and the ties between relationship and responsibility. Fisher and Tronto (1990: 40) define care as 'a species activity that includes everything that we do to maintain, continue, and repair our world so that we can live in it as well as possible. That world includes our bodies, ourselves, and our environment, all of which we seek to interweave in a complex, life sustaining web'. This perspective overcomes the boundaries of public and private spheres, embracing the social totality of relations, including human care relations and our ecological relationship with nature.

Against this background, the issue for social policy is not only that of promoting a work/life balance aimed at reconciling paid employment with other valuable activities. Rather, and more profoundly, we argue that it is possible to re-think the meaning of work both within and outside the labour market - through the lens of 'care'. Indeed, the narrative of care promotes a new paradigm, reimagining the meaning of social participation. This fundamentally changes the way in which we see work, whereby the latter can be redefined as the 'practice of taking care of the world' and put at the core of a new welfare state architecture (Laruffa, 2021). In this context, PI may be used as a policy lever for promoting the social and environmental sustainability of our societies. A PI would provide citizens with an 'exit option' from the labour market, allowing, encouraging and enabling them to participate in various reproductive and ecological activities and make valuable contributions that society greatly needs, ranging from the care of persons to the reparation of environmental degradation or the reinforcement of the democratic culture. Crucially, however, the ethics of care should also re-orient paid work itself, refocusing employment on the care for people and for the planet. Hence, the PI should not be understood as a substitute for interventions aimed at 'greening' employment.

The second reason for choosing the CA as a normative framework of reference lies in the importance it accords to democracy (e.g. Sen, 2009). From this perspective, the CA calls for democratising how social policies are designed and implemented. In particular, citizens should participate in defining the nature of the 'valuable activities' beyond employment. This 'democratic' approach is essential for developing a PI that successfully overcomes its critiques and potential drawbacks. This is in keeping with the anthropological understanding of individuals as multidimensional, comprising receivers, doers and 
judges of public action (cf Bonvin and Laruffa, 2021). Capability-enhancing policies should simultaneously conceive targeted individuals as 'receivers' of welfare benefits, where the latter are sufficiently generous for respecting their dignity; as 'doers', i.e. actors who flourish through valuable activities both within and beyond the labour market; and as 'judges', i.e. citizens who are capable and willing to express their aspirations and values and to participate in formulating the policies themselves. Our proposal of an eco-social PI combines these two insights: social policy should promote other valuable reproductive activities beyond employment and the precise content of these policies should be defined democratically.

\section{Conditionality, stigma and the administrative feasibility of PI}

Having outlined the normative desirability of an eco-social PI, in this section we focus on the policy challenges associated with putting a PI into practice, including how to specify the forms of 'participation' that count for the purposes of maintaining eligibility, and whether PI should be a universal or a means-tested payment. These questions are critical to understanding how different a PI is from either UBI or conventional workfare-oriented social assistance. Even more importantly, they speak to the concern about 'effective enforcement of a broad participation requirement' that De Wispelaere and Stirton, (2007: 524) argue would be administratively complex and costly, as well as potentially stigmatising if eligibility is conditioned on invasive bureaucratic assessments that give rise to the 'demeaning treatment' (Patrick and Simpson, 2020: 476) of claimants. Given the assumptions that 'far-reaching conditionality regimes' make about claimants and the forms of treatment they entail, Patrick and Simpson argue that supervisory forms of conditionality may simply be 'incompatible with dignified and respectful treatment' (2020: 485). 'Claims stigma' (Baumberg, 2015: 183) can be distinguished from how targeted income supports can also undermine dignity in a distributional sense. This occurs when payments are set so low as to deprive people of the resources to secure a minimum standard of living and participate fully in society. A core paradox of PI proposals is how to reconcile conditionality with a commitment to a welfare system that treats people with dignity and respect?

PI proposals, like all social policy, must deal with potential trade-offs between various goals underlying social security. These include alleviating poverty through affording people a decent standard of living and, in the context of an eco-social welfare state, enabling people to divert their time away from the productivist economy towards the performance of eco-social and reproductive labour. In pursuing these objectives social security measures must also function to preserve people's dignity and respect. An ecosocial PI must address these objectives simultaneously but there may be trade-offs between them. For example, where the objective of alleviating poverty is prioritised, this may point towards selective forms of income support that are narrowly targeted at those living close to or below the poverty line. So, the potential behavioural effects of a PI in diverting people's time away from productivist activity towards eco-social and reproductive labour would be diminished. Conversely, where the goal of promoting eco-social activity is prioritised as the core objective, this points towards more universal forms of income support with more tightly monitored behavioural conditions to ensure that recipients engage in eco-social labour. Yet widening the reach of any PI may undercut its political feasibility and affordability, raising the question of how such a social security reform could be financed. 
Moreover, the more tightly monitored participation requirements are, the greater the risk of 'relationally stigmatising' recipients by subjecting them to forms of administrative treatment that undermine their dignity. The key point is that there are tensions between the multiple policy objectives animating the reform of income supports in an eco-social context that need to be carefully navigated and balanced. Moreover, a PI will invariably be only one component of a much broader suite of welfare and tax reforms that are needed to support any eco-social transition. In particular, significant changes in income and/or consumption tax rates may be needed to motivate more affluent social groups to divert their time towards forms of eco-social participation and reproductive labour. Moreover, in recognising and rewarding these forms of participation at a policy level, a PI may also have wider spill over effects in terms of how eco-social and reproductive labour are societally valued so that productivist employment is no longer seen as 'the main vector of social inclusion' (Deranty, 2021: 3) or 'primary' civic duty (Patrick, 2012).

Whereas some see universal basic income as a catch-all alternative to both meanstested welfare and social insurance, Atkinson carefully positioned $\mathrm{PI}$ as complementary to unemployment insurance and state pensions. Social insurance would remain the default social security for many, enhancing the affordability and political feasibility of a PI that would 'cut dependence on means-tested benefits' (Atkinson, 1996: 67). Atkinson's key objection to means-testing was its application at household level in male-breadwinner systems. This denies women individual entitlement, a prerequisite for autonomy and equality. Income tests also create stigma and barriers to income support and lend themselves to paternalistic narratives of 'deserving' and 'undeserving' poor.

Ensuring an absence of stigmatising barriers is an important principle. However, both fiscal sustainability and political tactics may require that access to PI is limited by some financial threshold, while also ensuring stigma is at least mitigated by how any such threshold is applied. A PI income threshold, if not universal, can be designed so that it functions to selectively 'screen out' the most affluent citizens rather than as means of reserving support for only those suffering poverty and extreme deprivation. One could, for example, base circumstance thresholds on estimated minimum income or living wage standards, rather than close to the relative poverty line, as under conventional meanstested payments. ${ }^{2} \mathrm{PI}$ entitlements could also be gradually tapered on an individualised basis when a person's (rather than household's) income exceeds the relevant threshold. So, while a PI need not be universal, it must be widely available, individual, transparent to access, and set at a level that, in conjunction with access to universal basic services, enables people to meet essential needs.

Beyond the issue of means-testing, critics' key objection to PI relates to the practicalities of administratively enforcing conduct conditions. If participation is defined ambiguously, monitoring may become 'practically unworkable' and PI may become a form of UBI by default. Conversely, if participation is narrowly defined and strictly enforced, a PI will 'in practice bear a close resemblance to a workfare program' (De Wispelaere and Stirton, 2007: 526). Pérez-Muñoz argues that this 'rule section problem' generates two sources of arbitrariness: the danger that the criteria of participation will be defined to the disadvantage of 'those who depend most on this redistributive programme' and that the procedure for determining criteria will be 'non-transparent' (Pérez-Muñoz, 2016: 181). Below, we explore how a co-productive approach based on co-creating participation options at the local level might ameliorate this challenge. 


\section{Towards co-production and co-creation}

Activation is conventionally implemented through neoliberal paternalistic frameworks that treat claimants as passive, if not deviant, 'policy subjects' who must be 'resubjectificated' (Whitworth and Carter, 2014: 110) through case management and targeted sanctions. In this disciplinary context, claimants have few opportunities 'to exercise agency or shape the content of services' (Lindsay et al., 2019: 650). Concepts of coproduction and co-creation - often used synonymously with co-production - by contrast emphasise the importance of affirming citizens' agency in creating public value from the programmes they participate in. Following Verschuere et al. (2012), Lindsay et al. define co-production as 'the mix of activities that both public service agents and citizens contribute to the provision of public services' (2018: 574), although in more normative terms co-production encompasses an approach whereby outcomes are seen as co-created with citizens' active participation and where the contributions they make are 'substantial' (Loeffler and Timm-Arnold, 2020: 117). Extending this idea, Osborne et al. (2016: 644) argue that public services should be understood as 'holistic and dynamic' eco-systems whereby value is co-created within networks of delivery organisations, service users, their families, and communities. That is, value co-creation depends not just on the interactions between service users and frontline professionals but also on contributions from the wider social systems in which they are embedded.

From a public administration perspective, treating citizens as huge untapped resources' (Nabatchi et al., 2017: 770) is often defended pragmatically as enhancing service quality and efficiency, allowing problems to be understood in more nuanced ways 'than professionals acting alone' (Fung, 2015: 517) and increasing service use by promoting a sense of trust and ownership among users (Fledderus et al., 2014). However, from a capabilities perspective, the most important rationale is that co-production values citizen 'voice, choice and empowerment' (Lindsay et al., 2018: 583), recognising their agency as 'doers' and 'judges' who actively shape the institutions and policies that impact their lives. Here, co-production normatively mirrors the 'all-affected' principle of democratic legitimacy, that the voices of those affected by relationships of power should be heard 'and have an actual influence on' (Brandsen, 2021) the nature of political institutions.

Whether co-production is compatible with the 'legal compulsion' (Alford, 2016: 686) welfare conditionality entails is much debated (cf. Larsen and Caswell, 2020). If participation occurs under the threat of sanctions, any sense that it denotes a form of empowerment seems contradictory. The co-created, capability-oriented PI we propose moves away from enforcing participation through sanctions in favour of an enabling approach that relies on appealing to claimants' intrinsic motivations through the quality of participation options available. As discussed below, seeds of this approach are already evident in the reforms to Dutch social assistance under the 2015 Participation Act and subsequent 'trust experiments' (Muffels et al., 2019), as well as in recent experiments with co-creating employability services in Scotland (Lindsay et al., 2018) and Denmark (Larsen and Caswell, 2020).

Under the Netherland's decentralised model, municipal governments - who are responsible for disbursing national social assistance (SA) payments - enjoy autonomy to adjust how national social security policies are implemented. While benefit levels are nationally 'set in stone' by indexing payments to minimum wages (Groot et al., 2019: 
282), municipalities retain the power to determine participation requirements. Hence while the Participation Act enshrined stronger participation obligations, each municipality was responsible for determining what these requirements would be and how strictly they would be enforced (Groot et al., 2019). Many municipalities pursued a workfarist orientation based on strict monitoring and sanctions. However, discouraged by the low success rates of this approach, several experimented with new ways of implementing SA through 'trust experiments'. While retaining a core commitment to the expectation that all claimants should undertake socially useful activities, these municipalities opted to rely on intrinsic motivations to encourage participation.

Participation was interpreted broadly to encompass a wider range of contributions including education and volunteering. Advisors in welfare offices eschewed close monitoring in favour of trusting citizens not to misuse SA, and offering demand-oriented opportunities on the basis that building trust through the creation of participation opportunities 'is likely to be more effective in the longer run' (Muffels et al., 2019: 115). Accordingly, reintegration/participation plans were designed around claimants' own beliefs about which forms of participation were important. That is, participation criteria were co-created at the street-level rather than bureaucratically determined, and 'reciprocity was assumed' (Muffels, 2021: 155) rather than enforced. This did not render Dutch SA a form of UBI because eligibility remained restricted by conditions of 'circumstance' (i.e. means-testing) and 'category' (without social insurance) (see Clasen and Clegg, 2007).

Related experiments in co-creating participation plans with SA recipients have been pursued in municipalities in Scotland and Denmark. In Scotland, under the 'Making it Work' (MiW) program, councils in five local government areas partnered with third-sector organisations to develop employment support services for lone parent families based around principles of co-production. Like the Dutch 'trust experiments', the programme was based 'on a model of voluntary participation' (Lindsay et al., 2018: 576): it depended on the quality and range of employability as well as on the training activities made available, rather than the extrinsic threat of sanctions. Participant choice and control over individual action plans were the guiding principles of frontline delivery, while the lead provider organisations were embedded within area-based networks to support information sharing, signposting and greater responsiveness to participants' needs. Again, there was an underlying belief/trust that citizens would be intrinsically motivated to participate if they considered opportunities meaningful and worthwhile.

In Denmark, following a 2016 budget reform giving municipalities greater freedom to design how activation services were delivered, six municipalities moved towards an implementation model based on co-creation rather than the status-quo of the overall service goal being 'defined in advance' as employment (Larsen and Caswell, 2020: 16). In contrast to the employment services' traditional 'goal steering logic' focused on measuring activity through frequent meetings and progressions to employment: greater leeway was given to staff and citizens 'for genuine negotiation of which actions to take' (Larsen and Caswell, 2020: 16), recognising claimants' own knowledge as being of immense importance to co-creating successful outcomes.

The Dutch 'trust experiments', and related co-production initiatives in Scotland and Denmark, illustrate alternative ways of targeting social security that do not rely on strict conditionality and sanctions. In effect, they constitute an enabling rather than demanding approach to 'activating' participation, and the existing evaluation literature on these 
initiatives, while limited, indicates their potential for promoting participation while enhancing wellbeing (Dayson et al., 2017; Muffels, 2021). ${ }^{3}$

While these examples are encouraging, they also reveal some limitations in realising the proposal developed in this article. One limitation is that, given their employment orientation, they do not go far enough on the ecological side. An eco-social policy orientation would, however, affirm a broader reconceptualisation of participation that recognises the value of re-productive and ecological labour and provides opportunities for people to engage in activities that help to sustain people, the environment and the democratic polis rather than reducing reciprocity to only participating in employment, work experience or training. A fuller eco-social direction is found in Swaton's (2018) Ecological Transition Income proposal, which envisages a 'paradigm of co-construction and active partnership' between groups of engaged citizens, local governments, and nongovernment organisations in drawing up lists of activities required in the community that recipients could choose to undertake. Likewise, Stamm et al. (2020) highlight how potential for volunteering/participating in 'eco-social initiatives' - small-scale cooperative initiatives, that integrate social and environmental goals - can be actively enabled by income supports and social inclusion policies. Developing this point, Dukelow (2021) offers the example of Ireland's community employment programme, which enables income support recipients to undertake work embedded in community organisations and focussed on social rather than economic contributions.

A second difficulty concerns the transferability of this co-productive model to less ideal cultural-institutional contexts. Success depends on the degree to which this approach is embedded in background local network governance arrangements involving partnerships between public providers, community-based organisations, and other local stakeholders in co-planning a range of community development projects, work experience options, training opportunities and other activities for claimants to engage in. The above examples share common institutional features which enable intersections between co-production at the street-level and local collaborative partnerships. An important enabling condition in Denmark was the strength of municipalities' inter-organisational collaborations, and relationships with other service providers, through which they could make a wider range of opportunities available. The Netherland's Participation Act made each municipality responsible for determining what these requirements would be and how strictly they would be enforced (Groot et al., 2019: 281). Scotland's experiments in co-producing employability services likewise exhibited similar characteristics of strong inter-organisational collaboration and network governance arrangements as preconditions for co-production at the street-level. Moreover, as in Denmark and the Netherlands, where corporatism and strong partnerships between government and the public-sector have been features of their devolved approaches, Local Authority-led partnerships and 'a strong culture of partnership-working' (Lindsay et al., 2019: 650) are core to the Scottish model.

We find this proposed model of implementing PI through enabling co-production may thrive in certain institutional contexts. Although activating claimants has been a feature of social policies in each of Denmark, the Netherlands, and Scotland, none are vanguard workfare regimes. In Denmark, while activation policy has been influenced by developments in liberal workfare-oriented regimes, activation reforms have remained embedded in a universalist, social-democratic model (albeit one with strong corporatist elements) that sees labour market reintegration as a supplement rather than substitute for 
generous welfare benefits. Under what Torfing characterises as an 'offensive' workfarist orientation, progression through education and an emphasis on involving claimants in planning counselling and training activities that might empower them to improve their quality of life have historically been preferred to payment cuts and sanctions (Torfing, 1999; Damgaard and Torfing, 2010). Likewise, compared with the rest of the UK, Scotland has inclined towards a rights-based approach to welfare, enshrining a commitment to respect the dignity of individuals at the heart of its social security system (Patrick and Simpson, 2020). Compulsion through the threat of sanctions has been removed from devolved activation programmes as a step in this direction.

\section{Conclusion}

We have reinforced previous arguments in support of a PI as a central pillar of a capabilityoriented eco-social state in two ways. First, at the normative level, through combining the CA with an ethics of care we offered a perspective of an eco-social welfare state that would rebuild social policy around the goal of fostering citizens' 'capability to take care of the world' (Laruffa, 2021) and argued PI could constitute a key policy lever for achieving this goal. Nonetheless, as we have repeatedly insisted, a PI is just one among several policy levers that would be needed to enable a wider societal reconfiguration of work away from productivist employment and towards eco-social and reproductive labour. Still, it is an important step in this direction because it would entail that income supports no longer prevent people from engaging in eco-social activities by penalising reproductive labour and obligating claimants to sell their labour in the economy.

Second, at a more concrete level, we highlighted the political-administrative feasibility of our proposal. Our model envisages $\mathrm{PI}$ as a selective rather than fully universal form of income support which is limited through conditions of category (eligibility) and circumstance (individualised income-testing). It is an eco-social form of social assistance that displaces workfare-oriented forms of social assistance and is not a substitute for all forms of contributory social insurance and state pensions. So, unlike a UBI, an eco-social $\mathrm{PI}$ is a targeted benefit paid to people whose individual income is below a minimum income threshold and who reciprocate through eco-social labour and social reproductive. The individualised feature of PI is important for addressing gender equality as is the focus on targeting social reproduction, and particularly care, as a valued form of participation. While means-tested income support always carries the potential to demean and stigmatise claimants, we have suggested that stigmatisation can be reduced by a more individualised form of income-testing and higher thresholds that close the gap between the poverty line and a living wage. Furthermore, stigma is also reduced through the emphasis on cocreation/co-production, whereby citizens are respected as responsible agents, capable of self-reflection and commitment.

While retaining a commitment to the principle of reciprocity, we have argued against demanding models that enforce conditionality through strict sanctions in favour of an administrative emphasis on facilitating participation through co-production. This is essential to overcoming some crucial critiques of PI proposals, especially concerning the potential arbitrariness and intrusiveness of conditional basic income proposals. To demonstrate the feasibility of this proposal, we discussed three examples of co-created social assistance schemes that take this more enabling approach and adopt a broader view of 'participation' beyond employment. While these examples are encouraging, there is 
still some way to go to put the 'care of the world' at the core of social policy. Such a coproduced $\mathrm{Pl}$ is politically and administratively most feasible in welfare states with strong local autonomy, and partnership or networked governance alongside social-democratic elements anchored in a rights-based approach. Nonetheless, the countries examined (Denmark, Netherlands, and Scotland) represent all three of Esping-Andersen's (1990) nordic, continental and liberal regimes, suggesting the proposal has some transferability across welfare regimes.

Building upon our earlier attempts to develop the case for PI as an eco-social policy reform (McGann and Murphy, 2021), the model of PI developed in this article decouples social security from market participation, avoids the stigma of ex-ante, means-tested, household assessment, and affordably complements universal basic services, enabling citizens to live, work and care differently in a more equal and sustainable society. We hope that this article provides a small contribution to the debate on more emancipatory and sustainable alternatives to the status quo, nourishing our capability to imagine other possible worlds and more sustainable welfare models.

\section{Acknowledgements}

We are grateful to two anonymous reviewers for their insightful feedback on a previous draft of the article.

This research has received funding from the European Union's Horizon 2020 research and innovation programme under the Marie Sklodowska-Curie grant agreement no. 841477. It has also been supported by the Irish Research Council under Grant IRC/ COALESCE/2019/56/MURPHY and by the Swiss National Centre of Competence in Research 'LIVES - Overcoming Vulnerability: Life Course Perspectives', funded by the Swiss National Science Foundation [grant number 51 NF40-185901]. The views expressed are those of the authors alone. Neither Maynooth University, the University of Geneva, the European Commission, the Irish Research Council nor the Swiss National Science Foundation are responsible for any use that may be made of the information in this article.

\section{Notes}

1 The expression 'reason to value' in the definition of CA implies that this approach should not be confused with a libertarian project where all individuals' wishes are uncritically considered of equal worth: in the understanding of the CA adopted here only 'reasonable' preferences can claim public validity - and their 'reasonablesness' should be established through an open and inclusive dialogue (Bonvin and Laruffa, 2021).

2 In the UK, recent work estimates that the minimum income required by a single person of working age to meet essential needs is approximately $£ 314$ per week as opposed to an estimated relative poverty line (60 per cent of median income) of just under $£ 219$ before housing costs (Arnold et al., 2021).

3 For example, an evaluation of the Dutch trust experiments found more positive effects on participants' self-efficacy, subjective wellbeing and perceived health compared to the reference group, as well as more positive effects on participants' employment outcomes, reflecting the largely employmentoriented approach (Muffels, 2021). Evaluation of Scotland's MiW programme found positive impacts on participants' employment participation and wellbeing, with 30 per cent of lone parents entering paid employment and higher proportions again (36 to 39 per cent) reporting positive impacts on their confidence, self-esteem, and health (Dayson et al., 2017). 


\section{References}

Alford, J. (2016) 'Co-production, interdependence and publicness: extending public service-dominant logic', Public Management Review, 18, 5, 673-91.

Arnold, S., Harper, A. and Stirling, A. (2021) The UK's Living Standards: The Case for a Living Income, London: New Economics Foundation.

Atkinson, A. B. (1996) 'The case for a participation income', The Political Quarterly, 67, 1, 67-70.

Baumberg, B. (2015) 'The stigma of claiming benefits: a quantitative study', Journal of Social Policy, 45, 2, 181-99.

Bohnenberger, K. (2020) 'Money, vouchers, public infrastructures? A framework for sustainable welfare benefits', Sustainability, 12, 2, 596.

Bonvin, J.-M. and Laruffa, F. (2021) 'Towards a capability-oriented eco-social policy: elements of a normative framework', Social Policy and Society.

Brandsen, T. (2021) 'Vulnerable citizens: will co-production make a difference?', in E. Loeffler and T. Bovarid (eds.), The Palgrave Handbook of Co-Production of Public Services and Outcomes, Cham: Palgrave MacMillan, 527-39.

Clasen, J. and Clegg, D. (2007) 'Levels and levers of conditionality: measuring change within welfare states', in J. Clasen J and N. Siegel (eds.), Investigating Welfare State Change: The 'Dependent Variable Problem' in Comparative Analysis, Cheltenham: Edward Elgar Publishing, 166-97.

Damgaard, B. and Torfing, J. (2010) 'Network governance of active employment policy: the Danish experience', Journal of European Social Policy, 20, 3, 248-62.

Dayson, C., Pearson, S. and Sanderson, E. (2017) Evaluation of Making it Work: An Assessment of Impact and Value for Money, Sheffield: Centre for Regional Economic and Social Research, Sheffield Hallam University.

Deranty, J. P. (2021) 'Post-work society as an oxymoron: why we cannot, and should not, wish work away', European Journal of Social Theory, https://doi.org/10.1177/13684310211012169.

De Wispelaere, J. and Stirton, L. (2007) 'The public administration case against participation income', Social Service Review, 81, 3, 523-49.

Dukelow, F. (2021) 'What role for activation in eco-social policy', Social Policy and Society.

Esping-Andersen, G. (1990) The Three Worlds of Welfare Capitalism, Princeton: Princeton University Press.

Fisher, B. and Tronto, J. (1990) 'Toward a feminist theory of caring', in E. Abel and M. Nelson (eds.), Circles of Care: Work and Identity, Albany: SUNY Press, 35-62.

Fledderus, J., Brandsen, T. and Honingh, M. (2014) 'Restoring trust through the co-production of public services: a theoretical elaboration', Public Management Review, 16, 3, 424-43.

Fung, A. (2015) 'Putting the Public back into governance: the challenges of citizen participation and its future', Public Administration Review, 75, 4, 513-22.

Gilligan, C. (1993) In a Different Voice: Psychological Theory and Women's Development, Cambridge, MA: Harvard University Press.

Gough, I. (2021) 'Two scenarios for sustainable welfare: a framework for an eco-social contract', Social Policy and Society.

Groot, L., Muffels, R. and Verlaat, T. (2019) 'Welfare states' social investment strategies and the emergence of Dutch experiments on a minimum income guarantee', Social Policy and Society, 18, 2, 277-87.

Koch, M. (2018) 'Sustainable welfare, degrowth and eco-social policies in Europe', in B. Vanhercke, D. Ghailani and S. Sabato (eds.), Social Policy in the European Union: State of Play, Brussels: European Trade Union Institute and European Social Observatory, 37-52.

Koch, M. (2021) 'Social policy without growth: moving towards sustainable welfare states', Social Policy and Society, 1-13. https://doi.org/10.1017/S1474746421000361.

Larsen, F. and Caswell, D. (2020) 'Co-creation in an era of welfare conditionality: lessons from Denmark', Journal of Social Policy, https://doi.org/10.1017/S0047279420000665. 
Laruffa, F. (2020) 'What is a capability-enhancing social policy? Individual autonomy, democratic citizenship and the insufficiency of the employment-focused paradigm', Journal of Human Development and Capabilities, 21, 1, 1-16.

Laruffa, F. (2021) 'On the capability to take care of the world', Global Dialogue, 11, 1, 47-8, https:// globaldialogue.isa-sociology.org/on-the-capability-to-take-care-of-the-world/ [accessed 11.10.2021].

Lindsay, C., Pearson, S., Cullen, A. M. and Eadson, W. (2018) 'Street-level practice and the co-production of third sector-led employability services', Policy and Politics, 46, 2, 571-87.

Lindsay, C., Pearson, S., Batty, E., Cullen, A. M. and Eadson, W. (2019) 'Street-level practice, personalisation and co-production in employability: insights from local services with lone parents', Social Policy and Society, 18, 4, 647-58.

Loeffler, E. and Timm-Arnold, P. (2020) 'Comparing user and community co-production approaches in local 'welfare' and 'law and order' services: does the governance mode matter?', Public Policy and Administration, 36, 1, 115-37.

McGann, M. and Murphy, P. (2021) 'Income support in an eco-social state: the case for Participation Income', Social Policy and Society, https://doi.org/10.1017/S1474746421000397.

Muffels, R. (2021) 'Dutch local trust experiments: workfare or social investment - what works better and why?', in T. Laenen, B. Meuleman, A. Otto, F. Roosma and W. van Lancker (eds.), Leading Social Policy Analysis from the Front: Essays in Honour of Wim van Oorschot, Leuven: Acco Press, 151-68.

Muffels, R., Gielens, E. and Vos, S. (2019) 'Job search, employment capabilities and well-being of people on welfare in the Dutch 'Participation Income' experiments', in E. Muffels and E. Gielens (eds.), Empirical Research on an Unconditional Basic Income in Europe, Cham: Springer, 109-38.

Nabatchi, T., Sancino, A. and Sicilia, M. (2017) 'Varieties of participation in public services: the who, when, and what of coproduction', Public Administration Review, 77, 5, 766-76.

Nussbaum, M. C. (2011) Creating Capabilities: The Human Development Approach, Cambridge, MA: Harvard University Press.

Osborne, S. P., Radnor, Z. and Strokosch, K. (2016) 'Co-production and the co-creation of value in public services: a suitable case for treatment?', Public Management Review, 18, 5, 639-53.

Patrick, R. (2012) 'Work as the primary 'duty' of the responsible citizen: a critique of this work-centric approach', People, Place and Policy, 6, 1, 5-15.

Patrick, R. and Simpson, M. (2020) 'Conceptualising dignity in the context of social security: bottom-up and top-down perspectives', Social Policy and Administration, 54, 3, 475-90.

Pérez-Muñoz, C. (2016) 'A defence of participation income', Journal of Public Policy, 36, 2, 169-93.

Sen, A. (1999) Development as Freedom, New York: Knopf.

Sen, A. (2009) The Idea of Justice, Cambridge, MA: Belknap Press.

Stamm, I., Matthies, A. L., Hirvilammi, T. and Närhi, K. (2020) 'Combining labour market and unemployment policies with environmental sustainability? A cross-national study on ecosocial innovations', Journal of International and Comparative Social Policy, 36, 1, 42-56.

Swaton, S. (2018) 'For an ecological transition income', Green European Journal, https://www. greeneuropeanjournal.eu/for-an-ecological-transition-income/ [accessed 18,01.2021].

Torfing, J. (1999) 'Workfare with welfare: recent reforms of the Danish welfare state', Journal of European Social Policy, 9, 1, 5-28.

Tronto, J. (2013) Caring Democracy: Markets, Equality, and Justice, New York: New York University Press.

Verschuere, B., Brandsen, T. and Pestoff, V. (2012) 'Co-production: the state of the art in research and the future agenda', Voluntas, 23, 4, 1083-101.

Whitworth, A. and Carter, E. (2014) 'Welfare-to-work reform, power and inequality: from governance to governmentalities', Journal of Contemporary European Studies, 22, 2, 104-17. 